\title{
STUDY OF IRON TOXICITY IN RICE UNDER VARIED
}

\section{CONCENTRATIONS OF IRON SOLUTION}

\author{
T. MYTHILI ${ }^{1} \&$ S. JOTHIMANI ${ }^{2}$ \\ ${ }^{\text {I}}$ PG Scholar, Department of Soil Science and Agricultural Chemistry, Agricultural College and Research Institute, \\ Killikulam, Tamil Nadu Agricultural University, Coimbatore, Tamil Nadu, India \\ ${ }^{2}$ Professor, Department of Soil Science and Agricultural Chemistry, Agricultural College and Research Institute,
}

Killikulam, Tamil Nadu Agricultural University, Coimbatore, Tamil Nadu, India

\begin{abstract}
Irontoxicity is a wide spread nutrient disorder in the rice especially underrice-rice cropping system. The toxicity of iron is associated with reduced soil aeration due to submergence or flooded soils. It is caused by the high concentration of iron as $\mathrm{Fe}^{2+}$ in soil and it causes brown mottling symptom on leaves which spread downwards from the tip of the older leaves followed by the drying of entire leaves. An incubation experiment was conducted at Rice research station, Ambasamudram during Kar, 2018 to assess intensity of toxicity at different concentration of the ironic solution (0, 5, 10, 25, 50, 100, 250, $500 \mathrm{mg} \mathrm{L}^{-1}$ ) on four popularrice cultivars viz., ASD 16, ADT 45, ADT 39, TPS 5. The intensity of toxicity produced by various iron concentration levels were measured between active tillering and panicle initiation stage of the crop by following standard visual bronzing score developed by IRRI. The biometric characters such as plant height, specific leaf area (SLA), No. Of tillers/hill at $30^{\text {th }}, 60^{\text {th }}$ dayaftertransplantingwererecorded. The iron toxic symptom of bronzing was observed more under ASD 16 followed by ADT 45, ADT 39 and TPS 5. As the concentration of iron increases the plant height, specific leaf area and No. Of tillers/hill and biomass production were decreased. However, a rice grown at the iron concentration at 250 and $500 \mathrm{mg} \mathrm{L}^{-1}$ greatly reduced the growth and yield attributes viz tiller count, biomass production and Specific leaf area during $30^{\text {th }}$ and $60^{\text {th }}$ daysaftertransplanting.

KEYWORDS: Rice Iron Toxicity, Iron Nutrition, Bronzing \& Tolerance
\end{abstract}

Received: Mar 15, 2019; Accepted: Apr 05, 2019; Published: May 07, 2019; Paper Id.: IJASRJUN201925

\section{INTRODUCTION}

Iron $(\mathrm{Fe})$ toxicity is a major nutritional disorder in rice and affects yield and production in both rain fed and irrigated low land, especially in acidsoils. The cultivated area of low land rice is estimated to be around 128 million hectares of both irrigated and rainfedlowland (Maclean et al., 2002). Fe toxicity reduces rice yields by $12-49 \%$ depending on the tolerance of the rice cultivar, intensity of the stress, and soilfertility (Sahrawat, 2004). Complete crop failure can also occurunder severe Fe toxicity, especially at the seedling and early vegetative stages (Sahrawat, 2004; Becker and Asch, 2005). The toxicity of iron is associated with reduced soil aeration due to submergence or flooded soils. The occurrence of irontoxicity is due to various factors such as high iron content in soil and low $\mathrm{pH}$, high rainfall and low CEC. Under water logged condition, the soil undergoes reduction which reduces iron from $\mathrm{Fe}^{3+}$ to $\mathrm{Fe}^{2+}$ form, which is more soluble and concentration of $\mathrm{Fe}^{2+}$ in water logged rice soils become high and toxic to rice plants. The symptom is characterized by "bronzing" or "brown mottled" appears on older leaves followed by drying of entire leaves and entire plants under highertoxic level (Howeler, 1973). Therefore, the objective of this 
study is to assess the intensity of toxicity of differentiron concentration levels on bronzing symptoms, plant height, No. of tillers/hill, specific leaf area and biomass production of ricecrop. Asch et al., 2005 had developed a mechanistic screening method (early vegetative stage) that allows the investigation of actual tol erance mechanisms which have been used in this study.

\section{MATERIALS AND METHODS}

Experiment was conducted in a greenhouse at the Rice Research Station, Ambasamu dram during Kar, 2018. The design followed was a split plot with two replicates. The factors were four rice cultivars (ASD 16, ADT 45, ADT 39 and TPS 5) as main factor and eight $\mathrm{Fe}^{2+}$ levels (0 (control), 5, 10, 25, 50, 100, 250 and $\left.500 \mathrm{mg} \mathrm{L}^{-1}\right)$ as sub plots. Nine kg of soil was weighed and placed in 10-Liter pots and were thoroughly mixed with a basal fertilizer application. The soil at the site had $\mathrm{pH}$ of 5.1, Organic carbon content of $0.65 \%$; Bray P of $14.2 \mathrm{~kg}^{-1}$ ha; Potassium of $102 \mathrm{~kg}^{-1}$ ha; exchangeable Ca and Mg of 8.4 and 7.6 ppm; DTPA Fe of 316 ppm; with sandy clay loam in texture.

Plant samples with different degrees of bronzing were scored usingVisually bronzing score (VBS), using a scale of 1-9 (Table 1) based on the IRRI standard evaluation systems for rice (IRRI, 1988). A score of 1 indicated normal growth and tillering and 9 indicated on almost all plants were dying. At each sampling, leaves were scored for Fe-toxicity symptoms. The above ground biomass (leaf and stem separately) and root were harvested to determine dry matter accumulation. Air dried samples were oven-dried at $70^{\circ} \mathrm{C}$ (48 hours) to constant weight. The biometric parameters like plant height, Specific leaf area (SLA), No. of tillers/hill and biomass production were recorded at $30^{\text {th }}$ and $60^{\text {th }}$ daysaftertransplanting. The data were Statistically scrutinized by following standard computer tool (Pangae and Sukhatme, 1954).

Table 1: Score of the Leaf by Iron Toxicity Symptoms

\begin{tabular}{|c|c|}
\hline $\begin{array}{c}\text { Percentage Leaf } \\
\text { Area Affected }\end{array}$ & Score \\
\hline 0 & 0 \\
\hline $1-9$ & 1 \\
\hline $10-29$ & 3 \\
\hline $30-49$ & 5 \\
\hline $50-69$ & 7 \\
\hline $70-89$ & 9 \\
\hline $90-100$ & 10 (deadleaf) \\
\hline
\end{tabular}

\section{RESULTS AND DISCUSSIONS}

\section{Visual Bronzing Symptoms}

Visual bronzing symptoms were normally expressed as tiny brown spots on the lower leaves starting from the tip and drying downwards. The visual bronzing score was significantly influenced by both rice varieties and iron concentrations. In general, the Visual bronzing symptoms of all varieties ranged from 1 to 2 and 2 to 4 during vegetative and reproductive stages of rice respectively and the intensity of score (Table 2) increased with increase in iron concentration in both vegetative and reproductive stages. Abifarin, (1988) and Fageria and Rabelo, (1987) reported that visual bronzing scores (or brown spots) of rice cultivars vary with cultivars.

All the rice varieties expressed mean score of 2 during vegetative stages and the mean score was ranged from 2-4 for the rice variety at reproductive stage of the crop. This clearly indicates that the irontoxicity was expressed mostly 
during reproductive stage than vegetative stage. Among the rice varieties ASD 16 was most affected by irontoxicity followed by ADT 45, ADT 39 and TPS 5 especially at reproductive stage of the crop. This indicates the susceptibility of ASD 16 and other varieties are moderately resistant to iron toxicity. With respect to iron concentration, the VBS significantly increased with increasing iron concentration in irrigation water (Figure1 and 2) and had strong correlation $\mathrm{R}^{2}$ value of 0.974 and 0.968 on $30^{\text {th }}$ and $60^{\text {th }}$ DAT respectively. The higher concentration of 250 and $500 \mathrm{mg} \mathrm{L}^{-1}$ of iron produced more toxicity on rice foliage in the both vegetative and reproductive stage of the crop.

Table 2: Visual Bronzing Score of Rice Cultivars at the different Iron Concentration

\begin{tabular}{|c|c|c|c|c|c|c|c|c|c|c|}
\hline \multirow{2}{*}{$\begin{array}{c}\mathrm{Fe}^{2+} \\
\text { Concentration } \\
\left(\mathrm{mg} \mathrm{L}^{-1}\right) \text { in } \\
\text { Irrigation Water }\end{array}$} & \multicolumn{4}{|c|}{30 DAT } & \multirow[b]{2}{*}{ Mean } & \multicolumn{4}{|c|}{ 60 DAT } & \multirow[b]{2}{*}{ Mean } \\
\hline & $\begin{array}{c}\text { ASD } \\
16\end{array}$ & $\begin{array}{c}\text { ADT } \\
45\end{array}$ & $\begin{array}{c}\text { ADT } \\
\mathbf{3 9}\end{array}$ & $\begin{array}{c}\text { TPS } \\
5\end{array}$ & & ASD 16 & $\underset{45}{\text { ADT }}$ & $\begin{array}{c}\text { ADT } \\
\mathbf{3 9}\end{array}$ & $\begin{array}{c}\text { TPS } \\
5\end{array}$ & \\
\hline 0 (Control) & 1 & 0 & 1 & 1 & 1 & 2 & 1 & 1 & 1 & 1 \\
\hline 5 & 2 & 1 & 1 & 1 & 1 & 2 & 1 & 1 & 2 & 2 \\
\hline 10 & 3 & 1 & 2 & 1 & 2 & 3 & 1 & 2 & 2 & 2 \\
\hline 25 & 2 & 2 & 1 & 1 & 2 & 3 & 2 & 2 & 2 & 2 \\
\hline 50 & 2 & 1 & 3 & 2 & 2 & 3 & 2 & 2 & 3 & 3 \\
\hline 100 & 3 & 3 & 2 & 2 & 3 & 4 & 2 & 2 & 3 & 3 \\
\hline 250 & 3 & 2 & 2 & 3 & 3 & 5 & 2 & 3 & 3 & 3 \\
\hline 500 & 3 & 2 & 3 & 3 & 3 & 6 & 3 & 3 & 4 & 4 \\
\hline Mean & 2 & 2 & 2 & 2 & & 4 & 3 & 2 & 2 & \\
\hline $\mathrm{CD}(0.05)$ & & 0 & & & & & & 0.2 & & \\
\hline
\end{tabular}

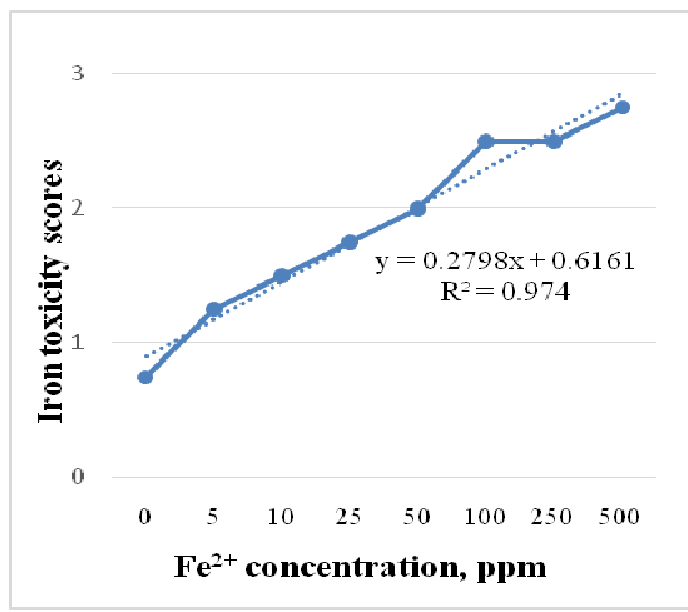

Figure 1: Visual Bronzing Score at $30^{\text {th }}$ DAT

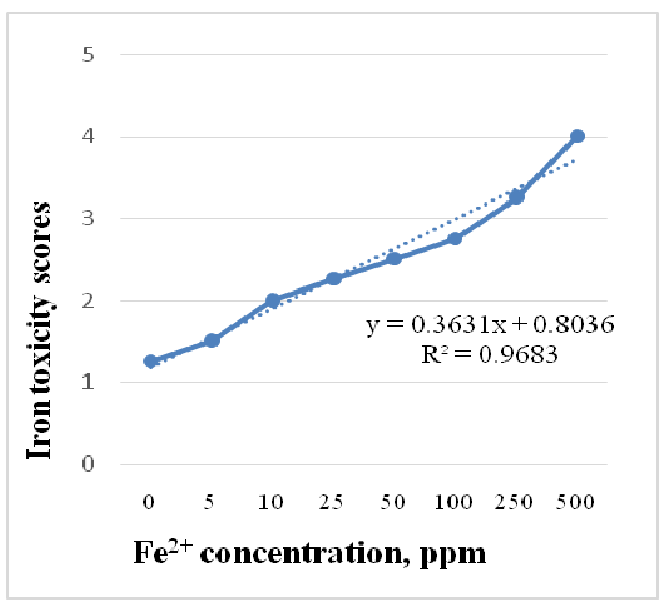

Figure 2: Visual Bronzing Score at $60^{\text {th }}$ DAT

\section{Biometric Parameter}

The biometric parameters such as plant height, No. of productive tillers, specific leaf area and biomass production were significantly influenced by both rice varieties and iron concentration in irrigation water at 30 and 60 day safter trans planting (Table 3). Among the rice varieties, the ASD 16 was taller $(30.5 \mathrm{~cm})$ and produced comparable tillers during early stages i.e., at 30 DAT and were on par with ADT 39 and ADT 45 where as the specific leaf area and Biomass production was higher in TPS 5 and ADT 39 in both the stages of crop. The variety TPS 5 and ADT 39 registered the more surface area of $28.8 \mathrm{~m}^{2}$ and $7.29 \mathrm{~m}^{2}$ at $30^{\text {th }}$ and $60^{\text {th }}$ DAT which showed medium to lerance to Fe toxicity. The significantly higher biomass of 3.29 and $9.52 \mathrm{~g} /$ plant was registered by ADT 39 at $30^{\text {th }}$ and $60^{\text {th }}$ DAT respectively. This clearly indicated that all the varieties except ADT 39 were affected by Fe toxicity. 
Table 3: Biometric Parameters of Rice as Influenced by Rice varieties and Fe Concentration at $30^{\text {th }}$ and $60^{\text {th }}$ DAT.

\begin{tabular}{|c|c|c|c|c|c|c|c|c|}
\hline Treatments & $\begin{array}{l}\text { Plant } \\
\text { Height } \\
\text { (cm) }\end{array}$ & $\begin{array}{c}\text { No. of } \\
\text { tillers/ } \\
\text { Hill }\end{array}$ & $\begin{array}{c}\text { SLA } \\
(\mathrm{cm} / \mathrm{g})\end{array}$ & $\begin{array}{c}\text { Biomass } \\
\text { Production at } \\
\text { 30 }^{\text {th }} \text { day } \\
\text { (g/Hill) }\end{array}$ & $\begin{array}{c}\text { Plant } \\
\text { Height } \\
\text { (cm) }\end{array}$ & $\begin{array}{l}\text { No. of } \\
\text { tillers/Hill }\end{array}$ & $\begin{array}{c}\text { SLA } \\
(\mathrm{cm} / \mathrm{g})\end{array}$ & $\begin{array}{c}\text { Biomass } \\
\text { Production } \\
\text { at } 60^{\text {th }} \text { day } \\
(\mathrm{g} / \mathrm{Hill})\end{array}$ \\
\hline & \multicolumn{4}{|c|}{30 DAT } & \multicolumn{4}{|c|}{ 60 DAT } \\
\hline \multicolumn{9}{|c|}{ Variety (V) } \\
\hline $\mathrm{V}_{1}(\mathrm{ASD} 16)$ & 30.50 & 8 & 11.43 & 2.486 & 64.00 & 20 & 5.738 & 8.680 \\
\hline $\mathrm{V}_{2}(\mathrm{ADT} 45)$ & 28.00 & 8 & 14.93 & 3.137 & 64.00 & 20 & 6.588 & 9.231 \\
\hline $\mathrm{V}_{3}$ (ADT 39) & 27.50 & 7 & 17.93 & 3.291 & 63.00 & 19 & 7.295 & 9.525 \\
\hline $\mathrm{V}_{4}(\mathrm{TPS} 5)$ & 27.00 & 7 & 28.81 & 2.814 & 59.00 & 19 & 6.834 & 9.067 \\
\hline C.D (0.05) & 0.497 & 0.446 & 0.773 & 0.143 & 1.385 & 1.268 & 0.108 & 0.306 \\
\hline \multicolumn{9}{|c|}{ Fe Concentration (ppm) } \\
\hline $\mathrm{Fe}_{0}$ & 30.00 & 8 & 41.25 & 2.422 & 61.00 & 18 & 6.017 & 7.817 \\
\hline $\mathrm{Fe}_{5}$ & 29.00 & 7 & 26.87 & 2.602 & 61.00 & 18 & 5.357 & 8.166 \\
\hline $\mathrm{Fe}_{10}$ & 29.00 & 8 & 16.50 & 2.828 & 62.00 & 19 & 5.567 & 8.730 \\
\hline $\mathrm{Fe}_{25}$ & 29.00 & 8 & 12.37 & 3.118 & 64.00 & 19 & 6.828 & 9.410 \\
\hline $\mathrm{Fe}_{50}$ & 29.00 & 9 & 15.25 & 3.341 & 64.00 & 20 & 7.971 & 9.720 \\
\hline $\mathrm{Fe}_{100}$ & 28.00 & 8 & 11.62 & 3.600 & 67.00 & 22 & 7.735 & 10.65 \\
\hline $\mathrm{Fe}_{250}$ & 27.00 & 7 & 9.750 & 3.035 & 62.00 & 21 & 7.527 & 9.627 \\
\hline $\mathrm{Fe}_{500}$ & 24.00 & 6 & 12.62 & 2.512 & 59.00 & 18 & 5.906 & 8.887 \\
\hline C.D (0.05) & 1.179 & 0.893 & 1.042 & 0.121 & 1.123 & 0.824 & 0.217 & 0.224 \\
\hline
\end{tabular}

\section{CONCLUSIONS}

With respect to iron concentration, the biometric characteristics such as plant height, No. of productive tillers/hill, Specific leaf area and biomass production were decreased with increasing concentration of Fe in irrigation water. The higher concentration of 500 ppm Fe greatly reduced the plant height, tiller density, Specificleaf area and biomass production especially at 60 DAT than 30 DAT. This shows that the higher irontoxicity reduced the yield parameters of rice.

\section{ACKNOWLEDGEMENTS}

I wish my sincere thanks and deepest gratitude to my Chairman Dr. S.Jothimani, Professor (Soil Science and Agricultural Chemistry), Agricultural College and Research Institute, Killikulam and I would like to express heart felt thanks to Dr. Arumugachamy, Professor and Head (Rice Research Station, Ambasamutharam) for providing necessary help for carrying out thisstudy.

\section{REFERENCES}

1. Abifarin, A. O. (1988). Grain yieldloss due to irontoxicity. WARDA Technical Newsletter. 8(1): 1-2.

2. Abifarin, A. O. (1989). Progress in Breeding Rice for Tolerance to IronToxicity. In: WARDA Annual Report West Africa Rice Development Association, Bouake, Cote d' Ivoire., 34- 39.

3. Asch, F., Becker, M and Kpongor, D. S. (2005). A quick and efficient screen for resistance to irontoxicity in lowlandrice. Journal of Plant Nutrition and Soil Science. 168 (6), 764-773.

4. Audebert, A., \& K. L. Sahrawat. (2000). Mechanism for IronToxicitytolerance in lowlandrice. Journal Plant Nutrition Soil Science, 23: $1877-1885$.

5. Audebert, A., \& M. Fofana. (2009). Rice yield gap due to irontoxicity in West Africa. Journal of Agronomy and Crop Science, 195: 66- 76. 
6. Sharma, R., Gangwar, R. K., Yadav, Vivek., \& Kumar, Rakesh. (2014). Response of basmati rice (Oryza sativa L.) cultivars to graded nitrogen levels under transplanted condition. International Journal of Research in Applied. Wo, 2, 33-38.

7. Elec, V., C. Quimio., R. Mendoza., A. Sajise., S. J. Beebout., G. Gregorio and R. Singh. (2013). Maintainingelevated Fe ${ }^{2+}$ concentration in solution culture for the development of a rapid and repeatable screening technique for irontoxicitytolerance in rice (Oryza sativa L.). Plant Soil,372: 253 - 264.

8. Fageria, N. K\& N. A. Rabelo. (1987). Tolerance of Rice Cultivars to IronToxicity. Journal of Plant Nutrient., 10 (6): 653 661.

9. Foy, C. D., R. L. Chaney., M. C. White. (1978). The Physiology of MetalToxicity in Plants. Ann. Rev. Plant Physiol., $29: 511-$ 566.

10. IRRI. (1988). Standard Evaluation System for Rice. International Rice Research Institute, Los Banos, Phillipines.

11. Sahrawat, K. (2004). Irontoxicity in wetlandrice and the role of othernutrients. Journal of Plant Nutrition., $27: 1471$ - 1504.

12. Manjappa, G. U., \& Hittalmani, S. (2014). Association analysis of drought and yield related traits in F2 population of Moroberekan/IR64 rice cross under aerobic condition. Int J Agric Sci Res, 4(2), 79-88.

13. Tanaka, A \& S. Yoshida. (1970). NutritionalDisorders of the Rice plant in Asia. IRRI Technical Bull. 10. International Rice Research Institute. Manila, Philippines.

14. Yoshida, S. (1981). Fundamentals of Rice Crop Science, International Rice Research Institute, Los Banos, Philippines. 
